\title{
Regulation of Fat Storage via Suppressed Thermogenesis: A Thrifty Phenotype That Predisposes Individuals with Catch-Up Growth to Insulin Resistance and Obesity
}

\author{
A.G. Dulloo \\ Department of Medicine, Division of Physiology, University of Fribourg, Fribourg, Switzerland
}

\author{
Key Words \\ Catch-up growth - Low birth weight - Obesity • \\ Thermogenesis - Type 2 diabetes
}

\begin{abstract}
Catch-up growth during infancy and childhood is increasingly recognized as a major risk factor for later development of insulin-related complications and chronic diseases, namely abdominal obesity, type 2 diabetes and cardiovascular disease. As catch-up growth per se is characterized by insulin resistance, hyperinsulinaemia and an accelerated rate of fat storage (i.e., catch-up fat) even in the absence of hyperphagia, the possibility arises that suppressed thermogenesis in certain organs/ tissues - for the purpose of enhancing the efficiency of catch-up fat - also plays a role in the pathophysiological consequences of catch-up growth. Here, the evidence for the existence of an adipose-specific control of thermogenesis, the suppression of which contributes to catchup fat, is reviewed. Recent findings suggest that such suppression of thermogenesis is accompanied by hyperinsulinaemia, insulin resistance in skeletal muscle and insulin hyperresponsiveness in adipose tissue, all of which precede the appearance of excess body fat, central fat distribution and elevations in intramyocellular triglyceride or circulating lipid concentrations. These findings
\end{abstract}

underscore a role for suppressed thermogenesis per se as an early event in the pathophysiology of catch-up growth. It is proposed that, in its evolutionary adaptive role to spare glucose for the rapid rebuilding of an adequate fat reserve (for optimal survival capacity during intermittent famine), suppressed thermogenesis in skeletal muscle constitutes a thrifty phenotype that confers to the phase of catch-up growth its high sensitivity to the development of insulin resistance and hyperinsulinaemia. In the context of the complex interactions between earlier reprogramming and a modern lifestyle characterized by nutritional abundance and low physical activity, this thrifty 'catch-up fat phenotype' is a central event that predisposes individuals with catch-up growth to abdominal obesity, type 2 diabetes and cardiovascular disease.

\section{Catch-Up Growth: A Risk Factor for Chronic Metabolic Diseases}

Catch-up growth, a physiological adaptation that reestablishes the genetically programmed growth trajectory, has long been viewed an essential feature of recovery from the deleterious effects of poor growth on development and health. During the past few years, however, 
several large epidemiological studies have suggested that catch-up growth may also be a long-term health hazard. These studies have indicated that people who were born small for gestational age (SGA) and/or whose growth faltered during infancy and childhood, but who subsequently show catch-up growth, have a higher propensity to develop abdominal obesity, type 2 diabetes and cardiovascular disease later in life [1-5].

The mechanisms by which catch-up growth could lead to such chronic diseases remain obscure. Theories include early (fetal or neonatal) 'programming', which postulate that food deprivation, malnutrition or other insults, particularly during critical periods of growth and development, can lead to lasting alterations in structures and functions of tissues, and in the resetting of major neuroendocrine systems [6,7]. Such programming or 'imprinting', although adaptive during a period of limited supply of nutrients, is thought to contribute to the increased risk of diseases during improved nutrition and catch-up growth later in life. Whatever the mechanisms by which such programming may predispose to chronic metabolic diseases, however, several lines of evidence point to the dynamic phase of catch-up growth per se as a state of insulin resistance.

\section{Catch-Up Growth: A State of Insulin Resistance}

A higher plasma insulin response to a glucose load during catch-up growth in infants and children born SGA is well established [8]. More recently, strong associations have been described between thinness during early infancy and an elevated plasma insulin concentration during catch-up growth later in childhood [9]. These findings, together with a recent prospective study from Chile indicating that reduced insulin sensitivity could be related to catch-up growth in infants born SGA as early as 1 year of age [10], highlight the fact that development of insulin resistance is an early feature of the mechanisms by which catch-up growth might confer increased risk of later diseases.

There is converging evidence suggesting that the insulin-resistant state of catch-up growth is intimately linked with a disproportionately faster rate of gaining body fat rather than muscle tissue [11]. This phenomenon of preferential 'catch-up fat' rather than catch-up of lean tissue, has long been reported in studies of rehabilitation in children after protein-energy malnutrition in developing countries (table 1), and has also been observed in children
Table 1. Selected studies in children and adults reporting a disproportionately faster rate of recovery of fat tissue (preferential catchup in fat mass) during weight gain, with lean tissue recovery lagging behind

\begin{tabular}{ll}
\hline Authors & $\begin{array}{l}\text { Population showing catch-up fat } \\
\text { during weight recovery/catch-up } \\
\text { growth }\end{array}$ \\
\hline Kornfeld and Schüller [12] & $\begin{array}{l}\text { Emaciated children recovering from } \\
\text { tuberculosis }\end{array}$ \\
\hline Debray et al. [13] & $\begin{array}{l}\text { Concentration camp prisoners } \\
\text { regaining weight }\end{array}$ \\
\hline Keys et al. [14] & Men after experimental starvation \\
\hline Weyer et al. [15] & $\begin{array}{l}\text { Men and women after 2 years of } \\
\text { limited food supply }\end{array}$ \\
\hline Forbes et al. [16] & Anorexics regaining weight \\
Mitchell and Truswell [17] & $\begin{array}{l}\text { Adults after substantial weight loss } \\
\text { due to protein-energy malnutrition }\end{array}$ \\
\hline Barac-Nieto et al. [18] & $\begin{array}{l}\text { Infants and children recovering } \\
\text { from protein-energy malnutrition }\end{array}$ \\
\hline Ashworth [19] \\
$\begin{array}{l}\text { MacLean and Graham [20] } \\
\text { Castilla-Serna et al. [21] }\end{array}$ & \begin{tabular}{l} 
Cancer patients \\
\hline van Eys [22]
\end{tabular} \\
\hline Streat et al. [23] & $\begin{array}{l}\text { Intensive-care patients with } \\
\text { septicaemia }\end{array}$ \\
\hline Kotler et al. [24] & parenteral nutrition \\
\hline
\end{tabular}

born SGA in developed countries. In a recent study conducted in Switzerland, prepubertal children born SGA were found to have more body fat and less lean tissue, as well as lowerglucose oxidation rates, than weight-matched controls [25]. These differences in body composition, associated with impaired glucose metabolism, may persist into adulthood, as suggested by studies from Finland indicating that for the same BMI, elderly individuals born SGA have 3-5 kg less lean tissue and more fat than agematched controls [26]. Also of particular interest in this context are recent findings from Denmark indicating that, relative to age-matched controls of similar BMI, healthy young men born SGA have slightly less lean tissue mass and slightly more body fat, but clearly higher abdominal fat mass [27]. They also show reduced forearm glucose uptake [28] and reduced muscle expression of key proteins involved in insulin signalling and glucose transport [29]. It is presently unknown whether these insulinrelated impairments in humans born SGA precede or are 
preceded by excess adiposity, preferential abdominal fat deposition or ectopic fat storage (accumulation of lipids in non-adipose tissues), all of which have been implicated in the development of insulin resistance [30]. However, these studies in infants, children and adults born SGA point to an early but long-lasting impairment in glucose homeostasis and body composition that can be related to preferential catch-up fat during catch-up growth.

\section{Preferential Catch-Up Fat: A Ubiquitous Phenomenon of Weight Recovery}

Of central importance to our understanding of the pathophysiology of catch-up growth, therefore, is the question of whether (and how) processes that regulate fat storage specifically during catch-up fat may lead to a state of insulin resistance. In addressing this issue, it is important to emphasize that this phenomenon of preferential catch-up fat is not limited to individuals born SGA or to the growth phase. As indicated in table 1, increases in the ratio of fat mass to lean mass are well documented in adults recovering body weight after weight loss due to a variety of conditions, including war-related famine, poverty-related undernutrition, experimental starvation, anorexia nervosa and other pathophysiological 'hypermetabolic' conditions such as cancer, septic shock and AIDS (see [11] for a review). Thus, a common denominator in many situations where there are large decreases in body weight followed by weight recovery - whether during growth or in adulthood - is that body fat is recovered at a disproportionately faster rate than lean tissue.

Explanations for this phenomenon of preferential catch-up fat have, in the past, centred upon inadequate intake of dietary protein or other nutrients for optimal protein deposition. Alternatively, the absolute amount of food consumed may greatly exceed the energy requirements for maintenance, tissue synthesis and physical work, such that the extra energy ingested is deposited as fat. However, the fact that catch-up fat persists in patients on well-balanced diets, often low in fat content, and independently of the level of dietary energy, protein and mineral and vitamin supplementation [11], underscores an increase in metabolic efficiency directed at fat deposition as a fundamental physiological process operating to accelerate fat recovery after growth retardation or weight loss. In other words, the phenomenon of catch-up fat seems to be a normal physiological process characterized by an elevation in the efficiency of cellular energy utilization.

\section{Regulation of Fat Storage during Catch-Up Fat: A Role for Suppressed Thermogenesis}

Evidence from experimental studies of prolonged starvation and refeeding in adult humans, as well as in actively growing animals, indicates that an elevated efficiency of fat deposition is a phenomenon that may occur at any age, and that it is a carry-over effect of the suppression of thermogenesis (i.e., energy conservation mechanisms) that occurred in the preceding period of food deprivation.

Reanalysis of longitudinal data on changes in basal metabolic rate (BMR) and body composition from the classic 'Minnesota experiment' of semi-starvation and refeeding [14] has suggested the existence of a control system linking depletion (or delayed expansion of fat stores) and suppressed thermogenesis [31]. In this study, 32 healthy men of normal body weight were subjected to 24 weeks of semi-starvation (during which they lost $25 \%$ of their initial body weight), followed by 12 weeks of restricted refeeding on diets relatively low in fat ( $\sim 20 \%$ fat by energy). As shown in figure 1, there is a positive relationship between the deviation in body fat and the change in adjusted BMR, an index of altered thermogenesis calculated from the change in BMR after adjusting for losses of fat-free mass and fat mass. In other words, the greater the degree of fat depletion during starvation, the greater the reduction in adjusted BMR and hence in the degree of suppression of thermogenesis. A similar relationship was also found after the 12-week period of restricted refeeding (i.e., the lower the degree of fat repletion, the greater the extent of reduction in residual BMR and hence the greater the degree of reduction in thermogenesis [31]). Taken together, the relationship between suppressed thermogenesis and fat depletion during phases of both weight loss and weight recovery indicates the operation of a control system with a negative feedback loop between thermogenesis and the state of depletion of fat stores. This has been referred to as 'adipose-specific control of thermogenesis' [32]; that is, a control system that has a slow time-constant by virtue of its response to signals arising only from the state of depletion/repletion of body fat stores. In this autoregulatory feedback system, signals from the depleted adipose fat stores exert a suppressive effect on thermogenesis.

More direct evidence for an adipose-specific suppression of thermogenesis, the role of which is to specifically accelerate body fat recovery, can be derived from studies of complete energy balance in growing rats regaining weight after semi-starvation (fig. 2). Under conditions 


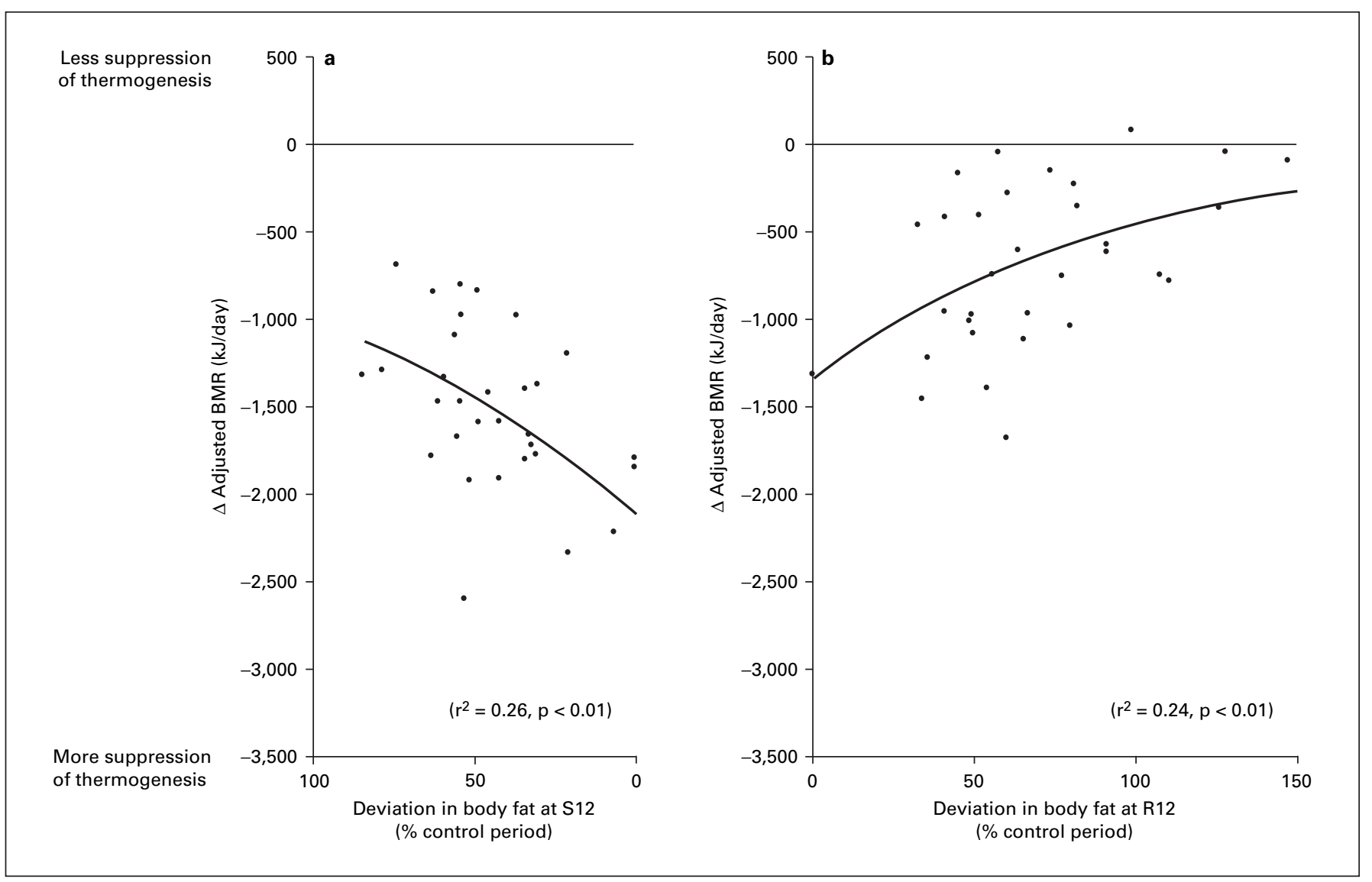

Fig. 1. Minnesota experiment of human starvation and refeeding revisited: the relationship between suppressed thermogenesis, assessed as change in basal metabolic rate (BMR) adjusted for changes in fat-free mass and fat mass, and the state of depletion of body fat stores during weight loss (a) (S12, week 12 of semi-starvation) and weight recovery (b) (R12, week 12 of restricted refeeding). Adapted from [32] with permission. The relationship between suppressed thermogenesis and fat depletion during phases of both weight loss and weight recovery suggests the operation of a control system with a negative feedback loop between thermogenesis and the state of depletion of fat stores.

whereby the rehabilitated rats were pair-fed to weightmatched controls, the rate of protein deposition was found to be the same as in controls, but that of fat deposition was increased by more than twofold. This was shown to be the result of $10-15 \%$ lower energy expenditure during the first $2-3$ weeks of isocaloric refeeding [32, 33]. A number of factors that could theoretically contribute to this difference in energy expenditure between refed and control rats (e.g., age difference, physical activity, feeding pattern) have been evaluated and shown to have a minimal impact on the difference in energy expenditure between the two groups. Consequently, under the conditions of our refeeding study, the lower energy expenditure in the refed rats is essentially a result of energy being spared due to sustained suppression of thermogenesis for the purpose of catch-up fat. These findings support the existence of an autoregulatory control system that participates in the regulation of catch-up growth by sustained suppression of thermogenesis, and suggest that energy thus conserved is directed specifically for the recovery of fat mass rather than that of lean tissue.

\section{Redistribution of Glucose from Skeletal Muscle to White Adipose Tissue during Catch-Up Fat}

As skeletal muscle is an important site for energy conservation during starvation, the control system underlying this 'adipose-specific control of thermogenesis' could 
Fig. 2. Sustained reduction in energy expenditure and accelerated fat deposition (catch-up fat) in a rat model of controlled refeeding after semi-starvation. Changes in body composition (a) and energy balance (b) were assessed over three successive periods of 10 days in refed animals pair-fed to weight-matched (WM) controls. The lower energy expenditure during refeeding persists for 2-3 weeks, and is due almost entirely to a sustained suppression of thermogenesis during weight recovery. Adapted from [32] with permission. $* \mathrm{p}<0.01$; ** $\mathrm{p}<0.001$ compared with WM controls.

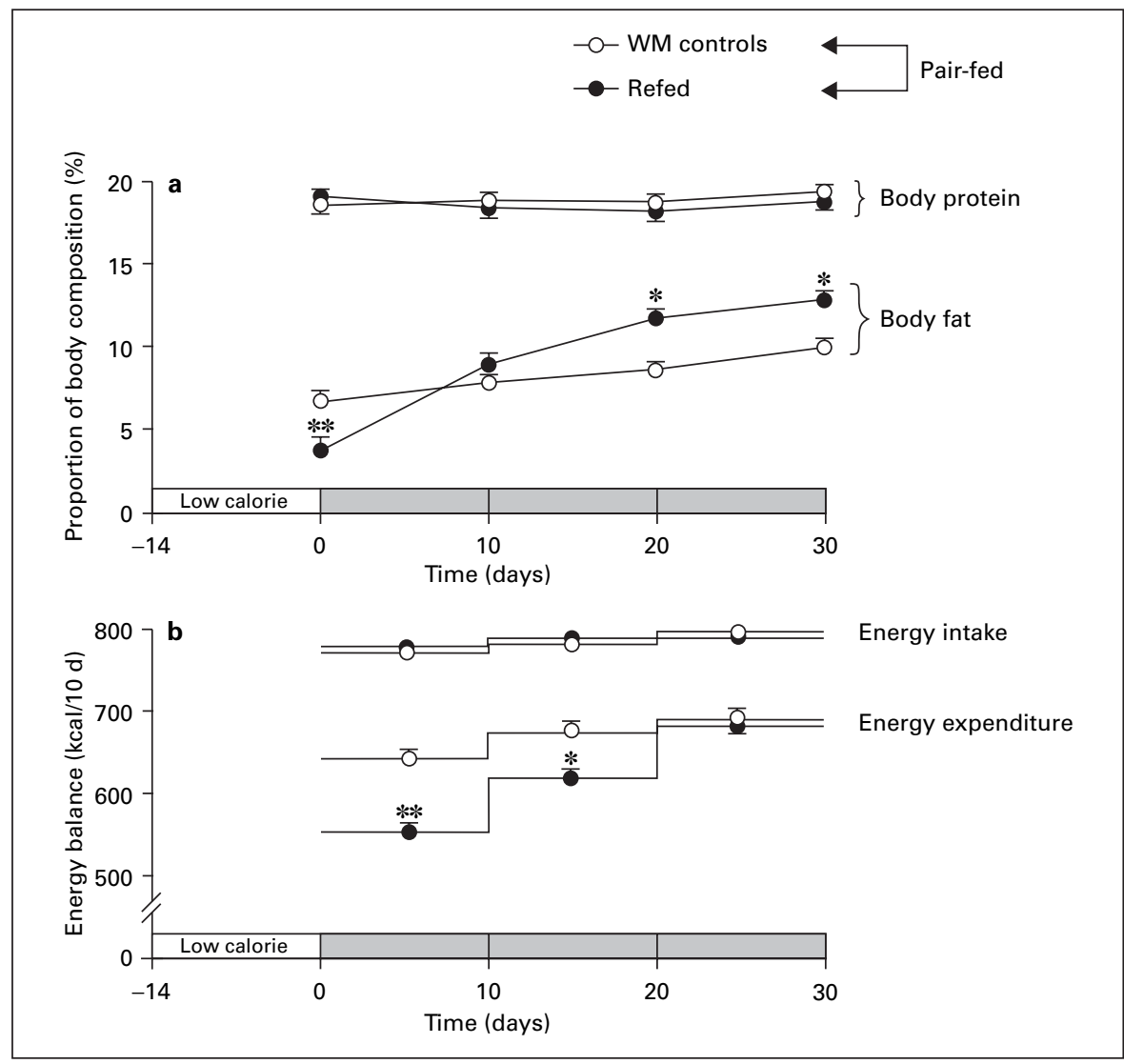

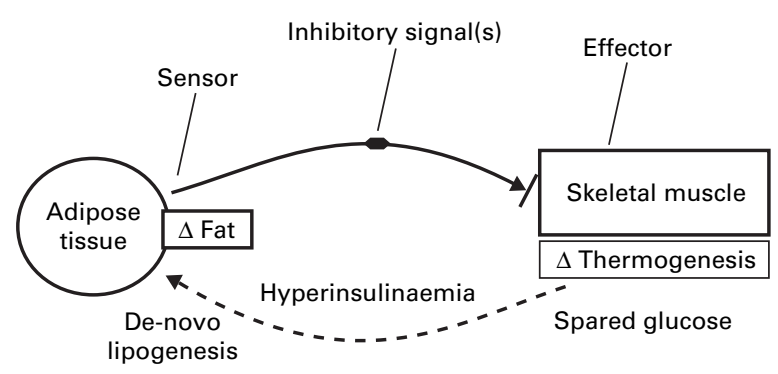

Fig. 3. Schematic representation of the adipose-specific control of thermogenesis. The suppression of thermogenesis in skeletal muscle, dictated solely by the state of depletion and repletion of the adipose tissue triglyceride stores, could underlie energy conservation directed specifically at accelerating fat recovery. This control system would hence comprise a sensor(s) of the state of depletion of the fat stores, a signal(s) dictating the suppression of thermogenesis as a function of the state of depletion of the fat stores, and an effector system mediating adaptive thermogenesis in skeletal muscle. operate as a feedback loop between adipose tissue triglyceride stores and skeletal muscle metabolism. As depicted in figure 3, it could comprise a sensor(s) of the state of depletion of the fat stores, signal(s) dictating the suppression of thermogenesis as a function of the state of depletion of the fat stores and an effector system mediating thermogenesis in skeletal muscle [32]. At present, our understanding of the components of this system is fragmentary. However, as skeletal muscle is the major site for insulin-mediated glucose disposal, a reduction in the metabolic rate of muscle would therefore result in a reduction in glucose utilization, leading to hyperinsulinaemia. This in turn, would serve to redirect the spared glucose towards de-novo lipogenesis and fat storage in adipose tissue.

Support for this 'glucose redistribution hypothesis' can be derived from our recent studies of the rat model of catch-up fat due to suppressed thermogenesis per se (shown in fig. 2), which indicate the following: (i) In response to a glucose load administered intraperitoneally, plasma insulin concentrations were clearly higher in the refed animals than in controls [34]. (ii) During hyperinsulinaemic-euglycaemic clamps in vivo, insulin-stimulat- 


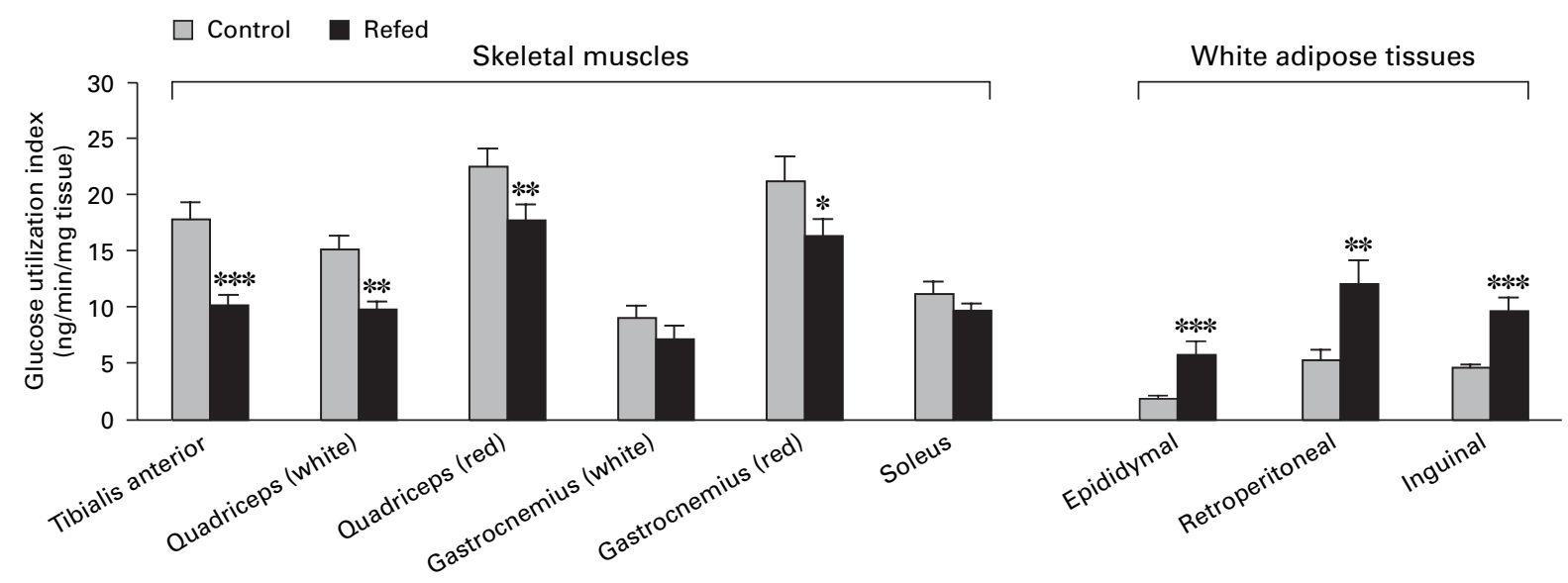

Fig. 4. Redistribution of glucose from skeletal muscle to adipose tissue during suppressed thermogenesis. Data are for glucose utilization rate as assessed by hyperinsulinaemic-euglycaemic clamps associated with labelled 2-deoxyglucose, in individual tissues from refed and control rats. All values are means \pm SEM $(n=7-9)$. $* \mathrm{p}=0.08 ; * * \mathrm{p}<0.05 ; * * * \mathrm{p}<0.001$ compared with controls. Adapted from [35] with permission.

ed glucose utilization in refed animals is lower in skeletal muscle (by 20-43\%) but higher in white adipose tissue (by two- to threefold) (fig. 4). This suggests a state of insulin resistance in skeletal muscle and insulin hyperresponsiveness in white adipose tissue [35]. (iii) Fatty acid synthase activity is higher in white adipose tissue from refed animals than from controls, thereby indicating enhanced conversion of glucose to lipids in fat stores [35].

Of particular importance in these studies comparing refed and control animals is that this redistribution of insulin-stimulated glucose utilization away from skeletal muscle towards de novo lipogenesis and fat storage in adipose tissue can be demonstrated in the absence of between-group differences in energy intake, lean tissue mass, total body fat mass, regional fat distribution or circulating free fatty acid concentrations [34]. Similarly, the state of insulin resistance in the skeletal muscle of the refed animals cannot be attributed to excess lipid storage in muscle cells, as histological staining of muscles revealed that intramyocellular lipid content in muscles from refed animals was not higher than in controls [35]. Taken together, these data suggest that the muscle insulin resistance and adipose tissue insulin hyperresponsiveness in the refed animals are not related to an excess substrate (free fatty acid) supply or to increased body fat or ectopic fat storage, but can be linked to the state of suppressed thermogenesis per se.

\section{Suppressed Thermogenesis Favouring Catch-Up Fat: A Thrifty Phenotype Turned Maladaptive}

The data presented here are consistent with the hypothesis that skeletal muscle, which is a major site for glucose disposal during adequate nutritional supply, is also important for energy conservation (and hence glucose sparing) for catch-up fat during weight recovery or catch-up growth. Within the context of weight recovery after growth retardation, the coordinated redistribution of glucose from skeletal muscle utilization to lipogenesis and fat storage in adipose tissue probably had survival value. It enables the rapid replenishment of fat stores (and hence, rapid restoration of survival capacity) without compromising blood glucose homeostasis under conditions of intermittent periods of food availability that prevailed during much of mammalian evolution.

Despite its 'adaptive' nature within the context of a lifestyle of famine-and-feast, this state may have deleterious consequences in the context of the modern lifestyle, characterized by low physical activity and energy-dense diets rich in fat and refined carbohydrates. In fact, a shift in diet from complex carbohydrates to animal fat and refined carbohydrates leads to an exacerbated suppression of thermogenesis, a more pronounced state of hyperinsu- 
Table 2. Role of suppressed thermogenesis in susceptibility to hyperinsulinaemia and glucose intolerance during catch-up growth in the rat. Data summarized from [35]

\begin{tabular}{llll}
\hline Diet & $\begin{array}{l}\text { Thermo- } \\
\text { genesis }\end{array}$ & $\begin{array}{l}\text { Plasma insulin } \\
\text { concentration }\end{array}$ & $\begin{array}{l}\text { Glucose } \\
\text { tolerance }\end{array}$ \\
\hline Low-fat & Suppressed & Elevated & $\begin{array}{l}\text { Normal } \\
\text { Euglycaemia }\end{array}$ \\
\hline High-fat & $\begin{array}{l}\text { Further } \\
\text { suppression }\end{array}$ & $\begin{array}{l}\text { Further } \\
\text { elevation }\end{array}$ & $\begin{array}{l}\text { Impaired } \\
\text { Hyperglycaemia }\end{array}$ \\
\hline
\end{tabular}

linaemia, hyperglycaemia and excess adiposity in animals recovering weight, compared with isocalorically fed controls growing spontaneously [34]. As depicted in table 2, high levels of (saturated) fat in the diet, even in the absence of hyperphagia, has compromised a complex homeostatic system. To what extent this disruption of glycaemia resides in the inability of adipose tissue to dispose of excess glucose spared as a result of an exacerbated suppression of thermogenesis during high-fat refeeding is currently being investigated in our laboratory.

\section{Molecular-Physiological Basis of Suppressed Skeletal Muscle Thermogenesis}

Our animal model of catch-up growth [34, 35] has shown that diminished thermogenesis in skeletal muscle is an early event in the pathogenesis of insulin resistance and the hyperinsulinaemic state of catch-up fat. The concentrations of key 'adiposity' hormones that might be implicated in the link between glucose metabolism and thermogenesis in skeletal muscle (namely insulin and leptin) are rapidly restored to (or above) control levels upon transition from starvation to refeeding [36]. Our current working hypothesis, therefore, is that the suppression of thermogenesis and concomitant insulin resistance in skeletal muscle are brought about through the inhibition of mechanisms by which these hormones interact to activate thermogenesis in skeletal muscle [36]. In this context, we recently reported that leptin can act directly on mouse skeletal muscle to stimulate thermogenesis by mechanisms that require intracellular signalling by adenosine monophosphate-activated protein kinase (AMPK) as well as phosphatidylinositol 3-kinase (PI3K), and that could involve an energy-dissipating substrate cycling between de novo lipogenesis and lipid oxidation [37]. The hypothesis that suppressed skeletal muscle thermogene- sis, which underlies preferential catch-up fat during catchup growth, is brought about through inhibition of intracellular signalling by AMPK and/or PI3K in skeletal muscle, is currently being tested.

\section{Conclusion}

The case is presented here that the process of catch-up growth per se (irrespective of earlier reprogramming) is a state characterized by a disproportionately greater rate of fat deposition relative to lean tissue deposition. This state of preferential catch-up fat is brought about, at least in part, via the suppression of thermogenesis that, as suggested by animal studies, is intricately associated with skeletal muscle insulin resistance. This suppressed thermogenesis precedes the appearance of excess body fat, central fat distribution and elevations in intramyocellular triglyceride or circulating lipid concentrations. These findings therefore underscore a potentially important role for suppressed thermogenesis per se in the pathophysiology of catch-up growth. It is proposed that, in its evolutionary adaptive role to spare glucose for the rapid rebuilding of an adequate fat reserve, suppressed thermogenesis in skeletal muscle constitutes a thrifty phenotype that confers to the phase of catch-up growth its high sensitivity towards the development of insulin resistance and hyperinsulinaemia. In the context of the complex interactions between earlier reprogramming and a modern lifestyle, this thrifty catch-up fat phenotype is a central event that predisposes individuals with catch-up growth to abdominal obesity, type 2 diabetes and cardiovascular disease.

\section{Acknowledgement}

This work is supported by the Swiss National Science Foundation (grant number 3200B0-10215). 


\section{References}

- Eriksson JG, Forsen T, Tuomilehto J, Winter PD, Osmond C, Barker DJ: Catch-up growth in childhood and death from coronary heart disease: longitudinal study. BMJ 1999;318: 427-431.

2 Cianfarani S, Germani D, Branca F: Low birthweight and adult insulin resistance: the 'catch-up growth' hypothesis. Arch Dis Child Fetal Neonatal Ed 1999;81:F71-F73.

-3 Huxley RR, Shiell AW, Law CM: The role of size at birth and postnatal catch-up growth in determining systolic blood pressure: a systematic review of the literature. J Hypertens 2000; 18:815-831.

$\checkmark 4$ Ong KK, Ahmed ML, Emmett PM, Preece MA, Dunger DB: Association between postnatal catch-up growth and obesity in childhood: prospective cohort study. BMJ 2000;320:967971.

-5 Levy-Marchal C, Jaquet D, Czernichow P: Long-term metabolic consequences of being born small for gestational age. Semin Neonatol 2004;9:67-74.

6 Hales CN, Barker DJ: The thrifty phenotype hypothesis. Br Med Bull 2001;60:5-20.

7 Young JB: Programming of sympathoadrenal function. Trends Endocrinol Metab 2002;13: 381-385.

8 Colle E, Schiff D, Andrew G, Bauer CB, Fitzhardinge P: Insulin responses during catch-up growth of infants who were small for gestational age. Pediatrics 1976;57:363-371.

-9 Ong KK, Dunger DB: Birth weight, infant growth and insulin resistance. Eur J Endocrinol 2004;151(suppl 3):U131-U139.

10 Soto N, Bazaes RA, Pena V, Salazar T, Avila A, Iniguez G, Ong KK, Dunger DB, Mericq MV: Insulin sensitivity and secretion are related to catch-up growth in small-for-gestational-age infants at age 1 year: results from a prospective cohort. J Clin Endocrinol Metab 2003;88:3645-3650.

11 Dulloo AG, Jacquet J, Montani JP: Pathways from weight fluctuations to metabolic diseases: focus on maladaptive thermogenesis during catch-up fat. Int J Obes Relat Metab Disord 2002;26(suppl 2):S46-S57.

12 Kornfeld W, Schüller H: Pattern of lean tissue deposition in free-living children recovering from tuberculosis. Z Kinder Jugend psychiatrie 1931;51:349-362.

13 Debray C, Zarakovitch M, Ranson B, Jacquemin J, Robert J, Sirage M: Contribution to the study on the pathology of the deportees. Sem Hôpital Paris 1946;22:863-870.

14 Keys A, Borizek J, Henschel A, Mickelson O, Taylor HL: The Biology of Human Starvation. Minneapolis, University of Minnesota Press, 1950.
15 Weyer C, Walford RL, Harper IT, Milner M, MacCallum T, Tataranni PA, Ravussin E: Energy metabolism after $2 \mathrm{y}$ of energy restriction: the biosphere 2 experiment. Am J Clin Nutr 2000;72:946-953.

16 Forbes GB, Kreipe RE, Lipinski BA, Hodgman $\mathrm{CH}$ : Body composition changes during recovery from anorexia nervosa: comparison of two dietary regimes. Am J Clin Nutr 1984; 40:1137-1145.

17 Mitchell PB, Truswell AS: Body composition in anorexia nervosa and starvation; in Beamont PJV, Burrows GD, Casper RC (eds): Handbook of Eating Disorders. I. Anorexia and Bulimia Nervosa. Amsterdam, Elsevier, 1987, pp 981-991.

18 Barac-Nieto M, Spurr GB, Lotero H, Maksud MG, Dahners HW: Body composition during nutritional repletion of severely undernourished men. Am J Clin Nutr 1979;32:981991.

19 Ashworth A: Metabolic rates during recovery from protein-calorie malnutrition: the need for a new concept of specific dynamic action. Nature 1969;223:407-409.

20 MacLean WC Jr, Graham GG: The effect of energy intake on nitrogen content of weight gained by recovering malnourished infants. Am J Clin Nutr 1980;33:903-909.

21 Castilla-Serna L, Perez-Ortiz B, Cravioto J: Patterns of muscle and fat mass repair during recovery from advanced infantile protein-energy malnutrition. Eur J Clin Nutr 1996;50: 392-397.

22 van Eys J: Nutrition and cancer: physiological interrelationships. Annu Rev Nutr 1985;5: 435-461.

23 Streat SJ, Beddoe AH, Hill GL: Aggressive nutritional support does not prevent protein loss despite fat gain in septic intensive care patients. J Trauma 1987;27:262-266.

24 Kotler DP, Tierney AR, Culpepper-Morgan JA, Wang J, Pierson RN Jr: Effect of home total parenteral nutrition on body composition in patients with acquired immunodeficiency syndrome. J Parenter Enteral Nutr 1990;14: 454-458.

25 Jornayvaz FR, Selz R, Tappy L, Theintz GE: Metabolism of oral glucose in children born small for gestational age: evidence for an impaired whole body glucose oxidation. Metabolism 2004; 53:847-851.

26 Eriksson J, Forsen T, Tuomilehto J, Osmond C, Barker D: Size at birth, fat-free mass and resting metabolic rate in adult life. Horm Metab Res 2002;34:72-76.

27 Rasmussen EL, Malis C, Jensen CB, Jensen JE, Storgaard H, Poulsen P, Pilgaard K, Schou JH, Madsbad S, Astrup A, Vaag A: Altered fat tissue distribution in young adult men who had low birth weight. Diabetes Care 2005;28:151153.
28 Hermann TS, Rask-Madsen C, Ihlemann N, Dominguez H, Jensen CB, Storgaard H, Vaag AA, Kober L, Torp-Pedersen C: Normal insulin-stimulated endothelial function and impaired insulin-stimulated muscle glucose uptake in young adults with low birth weight. J Clin Endocrinol Metab 2003;88:1252-1257.

29 Ozanne SE, Jensen CB, Tingey KJ, Storgaard $\mathrm{H}$, Madsbad S, Vaag AA: Low birthweight is associated with specific changes in muscle insulin-signalling protein expression. Diabetologia 2005;48:547-552.

30 Dulloo AG, Antic V, Montani JP: Ectopic fat stores: housekeepers that can overspill into weapons of lean body mass destruction. Int $\mathbf{J}$ Obes Relat Metab Disord 2004;28(suppl 4): S1-S2.

31 Dulloo AG, Jacquet J: Adaptive reduction in basal metabolic rate in response to food deprivation in humans: a role for feedback signals from fat stores. Am J Clin Nutr 1998;68:599_ 606.

32 Dulloo AG, Jacquet J: An adipose-specific control of thermogenesis in body weight regulation. Int J Obes Relat Metab Disord 2001;

25(suppl 5):S22-S29.
33 Dulloo AG, Girardier L: Adaptive role of energy expenditure in modulating body fat and protein deposition during catch-up growth after early undernutrition. Am J Clin Nutr 1993; 58:614-621.

34 Crescenzo R, Samec S, Antic V, Rohner-Jeanrenaud F, Seydoux J, Montani JP, Dulloo AG: A role for suppressed thermogenesis favoring catch-up fat in the pathophysiology of catch-up growth. Diabetes 2003;52:1090-1097.

- 35 Cettour-Rose P, Samec S, Russell AP, Summermatter S, Mainieri D, Carrillo-Theander C, Montani JP, Seydoux J, Rohner-Jeanrenaud F, Dulloo AG: Redistribution of glucose from skeletal muscle to adipose tissue during catch-up fat: a link between catch-up growth and later metabolic syndrome. Diabetes 2005; 54:751-756.

36 Dulloo AG: A role for suppressed skeletal muscle thermogenesis in pathways from weight fluctuations to the insulin resistance syndrome. Acta Physiol Scand 2005;184:295-307.

37 Dulloo AG, Gubler M, Montani JP, Seydoux J, Solinas G: Substrate cycling between de novo lipogenesis and lipid oxidation: a thermogenic mechanism against skeletal muscle lipotoxicity and glucolipotoxicity. Int J Obes Relat Metab Disord 2004;28(suppl 4):S29-S37. 